\title{
SURVEILLANCE OF MOSQUITOES (DIPTERA: CULICIDAE) IN RAJSHAHI, BANGLADESH
}

\section{Md. Tanvir Anjum Anik and Thahsin Farjana*}

Department of Parasitology, Faculty of Veterinary Science, Bangladesh Agricultural University, Mymensingh-2202, Bangladesh.

*Corresponding author: Thahsin Farjana; Email: thahsin.farjana@bau.edu.bd

ARTICLE INFO A B S T R A C T

Received

28 July, 2019

Revised

17 August, 2019

Accepted

28 August, 2019

Online

31 August, 2019

Key words

Mosquito

Culex

Anopheles

Surveillance

Rajshahi
Mosquitoes are considered the most important arthropod vectors in the world. Mosquito borne diseases are major public health problems in most of tropical and subtropical countries. An investigation was performed at Bagha upazila in Rajshahi district to identify the mosquito species and their breeding sites at the study area. Adult mosquitoes were collected by insect collecting net, light traps and human bait method and larvae were collected by dipper, mug, ladle spoon and dropper. A total of 1947 adult mosquitoes and 1376 larvae were collected and identified. Total ten species of adult mosquitoes and nine species of larvae under two genera were identified. The collected mosquitoes were belonging to two genera- Anopheles (An.) and Culex (Cx.). The identified species were $C x$. quinquefasciatus, $C x$. bitaeniorhynchus, Cx. tritaeniorhynchus, Cx. gelidus, Cx. pseudovishnui, Cx. whitmorei, $C x$. fuscanus, Cx. fuscocephala, An. aconitus, An. vagus and An. barbirostris. In both cases of larvae and adult mosquitoes, Culex was found more prevalent than Anopheles. In case of larvae the prevalence was $75.8 \%$ and $24.2 \%$, and in case of adult it was $71.2 \%$ and $28.8 \%$ for Culex and Anopheles, respectively. Among the all identified mosquitoes, Cx. quinquefasciatus showed the highest abundance in both cases of larval $(23.5 \%)$ and adult mosquitoes $(25.2 \%)$. From the survey it has been apparent that the Culex species may prefer the polluted water bodies in the locality like households, dairy sheds and drains whereas Anopheles species may prefer agricultural fields, and dairy sheds. This study will help to detect the breeding sites of mosquitoes in study areas and to take necessary steps to control mosquitoes and mosquito borne diseases.

To cite this article: Anik MTA and T Farjana, 2019. Surveillance of mosquitoes (Diptera: Culicidae) in Rajshahi, Bangladesh. Res. Agric. Livest. Fish. 6 (2): 329-336.

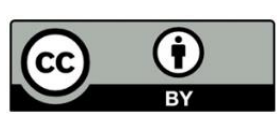

Copy right $\odot$ 2019. The Authors. Published by: AgroAid Foundation This is an open access article licensed under the terms of the Creative Commons Attribution 4.0 International License 


\section{INTRODUCTION}

Mosquitoes (Order Diptera: Family Culicidae) are the most important group of insects with regard to public health. Mosquitoes are responsible for the transmission of many medically important pathogens and parasites such as viruses, bacteria, protozoans, and nematodes, which cause serious diseases such as malaria, dengue, yellow and chikungunya fever, encephalitis or filariasis (Beaty and Marquardt 1996; Eldridge and Edman 2000). Mosquitoes are able to transmit pathogens due to their blood-sucking behaviour. In recent years, the distribution space of both mosquitoes and mosquito borne diseases has been changing and expanding for reasons such as increasing rates of environmental corruption, climatic changes, vector and pathogen resistance to insecticides and drugs, progressive urbanization and population movement (Patz et al., 1998). Rapid growth of human populations has been implicated in the increased presence of culicid vectors (Ravel et al., 2001). The present surveillance was carried out in Rajshahi district which is an endemic region for many mosquito borne diseases like lymphatic filariasis and dengue (CDC, 2012). Sporadic cases of malaria and yellow fever have been reported in Rajshahi (CDC, 2012). In Bangladesh two outbreaks of chikungunya were reported in 2008 and in 2011 and the first case was found in 2008 in northern Rajshahi Chapainawabganj district (ICDDR'B, 2009). In light of the emerging threat posed by mosquito-borne diseases is the ever growing need for vector control through mosquito surveillance and vector ecology research. These types of mosquito surveillance and research are considered significant in reducing mosquito borne diseases (Santiago and Claveria, 2012). Many mosquito species change their habitats, behavior and vectoral capacity, and some species acquire resistance against insecticides (Service, 1993). It is, therefore, essential to have knowledge about the abundance, seasonal variation and species composition of mosquitoes in the given area so as to perform and evaluate an effective mosquito control program.

In South Asian region like Bangladesh, the bionomics, ecology and epidemiological significance of many mosquito vectors remain poorly understood. Mosquito surveillance requires identification of mosquito fauna together with their breeding grounds particularly in areas with human settlements. Information on the diversity of mosquito fauna in an area can afterwards be used to formulate strategies for vector monitoring and control. Therefore, the present study was undertaken to identify the adult and larval mosquitoes and their breeding sites at Bagha Upazila in Rajshahi district of Bangladesh. This survey will provide useful information on the prevalence and distribution of mosquito species and their breeding site preference. Although the survey was limited at Bagha upazila in Rajshahi District, but basic information obtained will also applicable to other region in Bangladesh to conduct further research.

\section{MATERIALS AND METHODS}

This study was conducted to record the status of adult mosquito species as well as their breeding sites at Bagha upazila (Arani, Shahpur, Bausha, Jotrogoh) in Rajshahi district. Bagha Upazila located in between $24^{\circ} 07^{\prime}$ and $24^{\circ} 19^{\prime}$ north latitudes and in between $88^{\circ} 44^{\prime}$ and $88^{\circ} 55^{\prime}$ east longitudes. Larvae and adult mosquitoes were collected from Arani, Shahpur, Bausha, Jotrogoh area of Bagha Upazila of Sherpur district. These localities are densely populated and have good breeding grounds around them. Parts of these areas become inundated during the monsoon.

\section{Identification of breeding sites for mosquitoes}

Mosquitoes generally breed in stagnant water. So such types of places were given priority for larval collection. We searched for the breeding sites of mosquitoes in drains, broken pots, flower tubs, containers, bamboo stump, tree holes, fruit shells, ponds, tires, cow sheds, poultry farms, rice field, swampy areas, agricultural pits, construction pits, rice meals and saw meals etc.

\section{Mosquito larvae collection methods}

Larvae were collected by ladle spoon, pipette, dipper, mug and dropper from different spot and kept in a labeled plastic bottle and records were taken like collection date and time, and were brought to the laboratory for counting and identification. The collected larvae were brought to the laboratory in small plastic jars or bottle with water. During shipment care was taken so that the mosquito larva does not get shrinked or squished. 
Sample collection from breeding places was made at different periods of the day and from different situations. The most common and easiest technique to investigate the presence or absence mosquito larvae in a habitat is dipping. While dipping, care was taken so that shadow was cast away from the habitat as larvae are very sensitive and will dive to the bottom once shadow is cast on the water. The dipper was gently lowered in an angle of $45^{\circ}$ just below the surface so that water flows in together with any larvae that might be present.

\section{Adult mosquito collection methods}

Adult mosquitoes were collected by insect collecting net, mosquito spray, light trap and human bait etc. Collections were made different times in a day in each spot. Collection of mosquito was performed from outside the home by using insect collecting net and also using light traps (LTs) to collect the adults. Mosquitoes were collected by mosquito spray and bed nets from inside the house. Collected adult mosquitoes were kept in labeled plastic pot with $70 \%$ alcohol.

\section{Identifying methods of mosquitoes}

Mosquitoes were identified by simple method and by making permanent slides. In simple method, the sample was taken in a clean glass slide and then one or two drops paraffin was added and examined under Microscope using10X.

\section{Identification of mosquito species}

Mosquitoes (larvae and adult) were identified in the laboratory of Entomology, Dept. of Parasitology, BAU using the keys of Barraud (1934), Bram (1967)) and Tanaka et al. (1979). The mosquitoes were identified on the basis of their morphological characteristics.

\section{Statistical analysis}

Students "t" test was performed and the significance level of various mosquito species was calculated using statistical package SPSS-11.5.

\section{RESULTS AND DISCUSSION}

A total of 1376 larvae and 1947 adult mosquitoes were collected from different places of Bagha Upazilla during this study. Adults were collected by the help of insect collecting net, light traps as well as human bait method which is considered as one of the best methods for detecting and monitoring of mosquitoes. The larvae were collected by the help of dipper, mug, ladle spoon and dropper using a standard method (Meyer and Durso, 1998). Total nine species of mosquito larvae and ten species of adult mosquitoes under two genera were identified. The entire collected mosquitoes (adult and larva) were belonging to the family Culicidae. The identified two genera were- Anopheles (An.) and Culex (Cx.). The identified larvae were $C x$. quinquefasciatus, $C x$. tritaeniorhynchus, Cx. fuscanus, Cx. gelidus, Cx. pseudovishnui, Cx. bitaeniorhynchus, Cx. whitmorei, An. barbirostris and An. aconitus, and adult species were $C x$. quinquefasciatus, $C x$. tritaeniorhynchus, $C x$. bitaeniorhynchus, $C x$. fuscanus, $C x$. whitmorei, $C x$. fuscocephala, Cx. pseudovishnui, An. aconitus, An. barbirostris and An. vagus. The percentages of collected larval and adult mosquitoes have been shown in Table 1 and in Table 2.

Among the places, survey was conducted in tea stalls, flower vessels, can, broken jar, other stagnant water bodies to find Aedes mosquitoes. But Aedes mosquito was not found during the whole study period. Among the larval mosquitoes collected from the study area, Culex was $75.8 \%$ whereas Anopheles was $24.2 \%$. The larvae of $C x$. quinquifasciatus was found highest (23.5\%) among Culex species and An. aconitus was recorded highest (14.8\%) among Anopheles species (Table 1). In case of adult mosquitoes, $71.2 \%$ Culex and $28.8 \%$ Anopheles species were collected from different sites of the study area. Cx. quinquefasciatus (25.2\%) and An. aconitus (14.2\%) were found highest among adult Culex and Anopheles species, respectively (Table 2). In both cases Culex were more abundant than Anopheles during the study period and this prevalence of Culex species recorded in this study is similar to the findings of Akhter 2014, Farjana (2015) and Alam (2015) 
This survey indicates that because of the great abundance of Culex species in the study area, there is a high risk of filariasis and Japanese encephalitis in this region and the presence of Anopheles species indicates the risk of malaria infection. Previously Ameen and Moizuddin (1973) reported that CX. quinquefasciatus was the predominant species in Dhaka because the polluted organic-rich water in mosquito breeding places which is similar to the study area.

Table 1. Number of mosquito larvae $(n=1376)$ collected from Bagha upazila, Rajshahi

\begin{tabular}{|llll|}
\hline Sub family & Species & No. of mosquitoes & Percentage (\%) \\
\hline Culicinae & Cx. quinquefasciatus & 324 & 23.5 \\
& Cx. bitaeniorhynchus & 59 & 4.2 \\
& Cx. fuscanus & 263 & 19.1 \\
& Cx. pseudovishnui & 63 & 4.5 \\
& Cx. tritaeniorhynchus & 170 & 12.3 \\
& Cx. whitmorei & 69 & 5.1 \\
Cx. gelidus & 96 & 6.9 \\
Sub total & An. aconitus & 1044 & 75.8 \\
Anophelinae & 204 & 14.8 \\
An. barbirostris & 128 & 9.3 \\
\hline
\end{tabular}

Table 2. Number of adult mosquitoes ( $n=1947)$ collected from Bagha upazila, Rajshsahi

\begin{tabular}{|llll|}
\hline Sub family & Species & No. of mosquitoes & Percentage (\%) \\
\hline Culicinae & Cx. quinquefasciatus & 488 & 25.2 \\
Cx. bitaeniorhynchus & 123 & 6.3 \\
& Cx. fuscanus & 269 & 13.8 \\
& Cx. fuscocephala & 93 & 4.7 \\
& Cx. tritaeniorhynchus & 161 & 8.2 \\
& Cx. pseudovishnui & 64 & 3.2 \\
Cx. whitmorei & 187 & 9.6 \\
Sub total & An. aconitus & $\mathbf{1 3 8 5}$ & $\mathbf{7 1 . 2}$ \\
Anophelinae & 277 & 14.2 \\
An. barbirostris & 190 & 9.7 \\
An. vagus & 95 & 4.8 \\
& & 562 & $\mathbf{2 8 . 8}$ \\
\hline
\end{tabular}


Table 3. Distribution of mosquito larvae in Bagha upazila, Rajshsahi

\begin{tabular}{|c|c|c|c|c|c|c|c|c|c|c|c|c|c|c|}
\hline | & Species & & HP & $\mathrm{HH}$ & BZR & STN & DRNs & DS & PF & $\mathbf{R M}$ & AGF & PN & MG & SM \\
\hline \multirow[t]{2}{*}{1.} & Cx. quinquefasciatus & No. & 48 & 7 & 40 & 6 & 155 & 33 & 9 & 17 & 3 & 12 & 24 & 15 \\
\hline & & $\%$ & 3.5 & 0.5 & 2.9 & 0.5 & 11.3 & 2.4 & 0.7 & 1.2 & 0.2 & 0.9 & 1.7 & 1.1 \\
\hline \multirow[t]{2}{*}{2.} & Cx. bitaeniorhynchus & No. & 9 & 0 & 5 & 0 & 68 & 4 & 0 & 0 & 0 & 0 & 9 & 4 \\
\hline & & $\%$ & 0.7 & 0 & 0.5 & 0 & 4.9 & 0.3 & 0 & 0 & 0 & 0 & 0.7 & 0.3 \\
\hline \multirow[t]{2}{*}{3.} & Cx. fuscanus & No. & 29 & 15 & 32 & 13 & 77 & 10 & 10 & 3 & 5 & 9 & 9 & 0 \\
\hline & & $\%$ & 2.1 & 1.1 & 2.3 & 1.0 & 5.6 & 0.8 & 0.8 & 0.2 & 0.5 & 0.7 & 0.7 & 0 \\
\hline \multirow[t]{2}{*}{4.} & Cx. pseudovishnui & No. & 21 & 0 & 0 & 3 & 2 & 2 & 12 & 0 & 0 & 4 & 12 & 7 \\
\hline & & $\%$ & 1.5 & 0 & 0 & 0.2 & 0.1 & 0.1 & 0.9 & 0 & 0 & 0.3 & 0.9 & 0.6 \\
\hline \multirow[t]{2}{*}{5.} & Cx. tritaeniorhynchus & No. & 38 & 3 & 20 & 0 & 28 & 47 & 18 & 5 & 60 & 0 & 11 & 0 \\
\hline & & $\%$ & 2.8 & 0.2 & 1.5 & 0 & 2.0 & 3.5 & 1.3 & 0.5 & 4.5 & 0 & 0.9 & 0 \\
\hline \multirow[t]{2}{*}{6.} & Cx. whitmorei & No. & 9 & 1 & 6 & 1 & 5 & 2 & 2 & 0 & 0 & 17 & 8 & 0 \\
\hline & & $\%$ & 0.7 & 0.07 & 0.5 & 0.07 & 0.5 & 0.1 & 0.1 & 0 & 0 & 1.2 & 0.6 & 0 \\
\hline \multirow[t]{2}{*}{7.} & Cx. gelidus & No. & 31 & 2 & 0 & 0 & 0 & 21 & 1 & 2 & 13 & 1 & 12 & 7 \\
\hline & & $\%$ & 2.3 & 0.1 & 0 & 0 & 0 & 1.5 & 0.07 & 0.1 & 1.0 & 0.07 & 0.9 & 0.6 \\
\hline \multirow{2}{*}{\multicolumn{2}{|c|}{ Culex }} & No. & 185 & 28 & 103 & 23 & 335 & 119 & 52 & 27 & 81 & 43 & 85 & 33 \\
\hline & & $\%$ & 13.4 & 2.0 & 7.5 & 1.7 & 24.3 & 8.6 & 3.8 & 2.0 & 5.9 & 3.1 & 6.1 & 2.4 \\
\hline \multirow[t]{2}{*}{8.} & An. aconitus & No. & 19 & 4 & 2 & 7 & 23 & 40 & 19 & 2 & 65 & 0 & 12 & 11 \\
\hline & & $\%$ & 1.4 & 0.3 & 0.1 & 0.6 & 1.7 & 2.9 & 1.4 & 0.1 & 4.7 & 0 & 0.9 & 0.8 \\
\hline \multirow[t]{2}{*}{9.} & An. barbirostris & No & 6 & 11 & 27 & 1 & 3 & 15 & 0 & 0 & 54 & 2 & 8 & 1 \\
\hline & & $\%$ & 0.5 & 0.8 & 2.0 & 0.07 & 0.2 & 1.1 & 0 & 0 & 3.9 & 0.1 & 0.6 & 0.07 \\
\hline \multirow{2}{*}{\multicolumn{2}{|c|}{ Anopheles }} & No. & 25 & 15 & 29 & 8 & 26 & 55 & 19 & 2 & 119 & 2 & 20 & 12 \\
\hline & & $\%$ & 1.8 & 1.1 & 2.1 & 0.6 & 1.9 & 4.0 & 1.4 & 0.1 & 8.6 & 0.1 & 1.1 & 0.9 \\
\hline \multirow{2}{*}{\multicolumn{2}{|c|}{ Sub total }} & No. & 230 & 43 & 162 & 31 & 351 & 179 & 71 & 29 & 133 & 45 & 105 & 45 \\
\hline & & $\%$ & 16.7 & 3.1 & 11.8 & 2.3 & 25.5 & 13.0 & 5.2 & 2.1 & 9.7 & 3.3 & 7.6 & 3.3 \\
\hline \multicolumn{2}{|c|}{ Total } & 1376 & & & & & & & & & & & & \\
\hline
\end{tabular}

***House hold $(\mathrm{HH})$, Hospital (HP), Bazar (BZR), Station (STN), Large Drain (DRN), Dairy shed (DS), Poultry farm (PF), Agricultural field (AGF), Pond (PN), Mango garden (MN), Saw mill (SM), Rice mill (RM)

Among the Culex mosquitoes, in both cases of larvae (23.5\%) and adult $(25.2 \%)$, Cx. quinquefasciatus showed highest abundance in the study area followed by $C x$. fuscanus $(19.1 \%$ and $13.8 \%$, in case of larvae and adult, respectively).The cosmopolitan Cx. quinquefasciatus is a known vector of Bancroftian filariasis in Tropical Americas, in Tropical Africa, and in Asia (Manguin et al., 2009). On the other hand, both larva and adults of An. aconitus was found more abundant in the study area among the Anopheles species. The larval and adult mosquitoes found in different habitats of Bagha upazila such as cattle shed, poultry shed, agricultural field, bazar, rail station, saw mill, rice mill, hospital have been shown in Table 3 and Table 4. Larvae of $C x$. quenquifaciatus were found more abundant in large drains (11.3\%) followed by hospitals (3.5\%) and Bazars (2.9\%) of different places of Bagha Upazilla of Rajshahi District. All Culex larvae were found more concentrated in the drains of the study area, except $C x$. tritaeniorhynchus was found more prevalent in rice fields. On the other hand, the highest prevalence of Anopheles larvae was found in agricultural field (8.6\%) followed by dairy sheds $(4.0 \%)$ and drains $(2.1 \%)$. Irrigated rice fields which make up the largest man-made wetland environment in the world have been associated with many mosquito-borne diseases in many countries (WHO, 1996). 
Table 4. Distribution of adult mosquitoes in Bagha Upazila, Rajshahi

\begin{tabular}{|c|c|c|c|c|c|c|c|c|c|c|c|c|c|}
\hline $\begin{array}{l}\text { SI } \\
\text { no }\end{array}$ & Species & & HH & HP & BZR & STN & DRN & DS & PF & RM & AGF & MG & SM \\
\hline \multirow[t]{2}{*}{1.} & Cx. quinquefasciatus & No. & 198 & 67 & 30 & 58 & 152 & 107 & 19 & 27 & 3 & 24 & 5 \\
\hline & & $\%$ & 12.7 & 3.4 & 2.1 & 2.9 & 8.9 & 5.5 & 0.9 & 1.4 & 0.2 & 1.2 & 0.3 \\
\hline \multirow[t]{2}{*}{2.} & Cx. bitaeniorhynchus & No. & 26 & 0 & 5 & 0 & 68 & 54 & 0 & 0 & 0 & 9 & 4 \\
\hline & & $\%$ & 1.3 & 0 & 0.3 & 0 & 3.5 & 2.8 & 0 & 0 & 0 & 0.5 & 0.2 \\
\hline \multirow[t]{2}{*}{3.} & Cx. fuscanus & No. & 39 & 15 & 32 & 33 & 77 & 10 & 10 & 13 & 5 & 0 & 0 \\
\hline & & $\%$ & 2.0 & 0.8 & 1.6 & 1.6 & 4.0 & 0.5 & 0.5 & 0.6 & 0.3 & 0 & 0 \\
\hline \multirow[t]{2}{*}{4.} & Cx. pseudovishnui & No. & 41 & 0 & 0 & 3 & 12 & 23 & 7 & 0 & 0 & 12 & 2 \\
\hline & & $\%$ & 2.0 & 0 & 0 & 0.2 & 0.6 & 1.8 & 0.6 & 0 & 0 & 0.6 & 0.1 \\
\hline \multirow[t]{2}{*}{5.} & Cx. tritaeniorhynchus & No. & 78 & 15 & 20 & 0 & 28 & 62 & 3 & 5 & 4 & 11 & 0 \\
\hline & & $\%$ & 4 & 0.8 & 1.0 & 0 & 1.4 & 3.1 & 0.2 & 0.3 & 0.2 & 0.6 & 0 \\
\hline \multirow[t]{2}{*}{6.} & Cx. whitmorei & No. & 9 & 1 & 6 & 1 & 15 & 2 & 2 & 0 & 0 & 8 & 0 \\
\hline & & $\%$ & 0.5 & 0.05 & 0.3 & 0.05 & 0.8 & 1.0 & 1.0 & 0 & 0 & 0.4 & 0 \\
\hline \multirow[t]{2}{*}{7.} & Cx. gelidus & No. & 41 & 2 & 0 & 0 & 0 & 21 & 1 & 0 & 0 & 0 & 0 \\
\hline & & $\%$ & 2 & 1 & 0 & 0 & 0 & 1 & 0.05 & 0 & 0 & 0 & 0 \\
\hline \multirow{2}{*}{\multicolumn{2}{|c|}{ Culex }} & No & 432 & 101 & 93 & 95 & 352 & 258 & 42 & 45 & 12 & 64 & 11 \\
\hline & & $\%$ & 22.2 & 5.2 & 4.8 & 4.8 & 18.0 & 13.3 & 2.2 & 2.2 & 0.6 & 3.3 & 0.6 \\
\hline \multirow[t]{2}{*}{8.} & An. aconitus & No. & 29 & 4 & 2 & 7 & 23 & 40 & 9 & 12 & 57 & 7 & 2 \\
\hline & & $\%$ & 1.5 & 0.2 & 0.1 & 0.4 & 2.4 & 2 & 0.5 & 0.6 & 3 & 0.4 & 0.1 \\
\hline & An. barbirostris & No. & 10 & 11 & 34 & 1 & 30 & 15 & 0 & 0 & 43 & 4 & 0 \\
\hline & & $\%$ & 0.5 & 0.5 & 1.6 & 0.5 & 1.2 & 0.8 & 0 & 0 & 2.2 & 0.2 & 0 \\
\hline \multirow[t]{2}{*}{10.} & An. vagus & No & 6 & 0 & 10 & 0 & 3 & 50 & 0 & 0 & 27 & 0 & 0 \\
\hline & & $\%$ & 0.4 & 0 & 0 & 0 & 0.2 & 2.6 & 0 & 0 & 1.4 & 0 & 0 \\
\hline \multirow{2}{*}{\multicolumn{2}{|c|}{ Anopheles }} & No & 45 & 15 & 46 & 8 & 56 & 105 & 9 & 12 & 127 & 11 & 2 \\
\hline & & $\%$ & 2.2 & 0.8 & 2.2 & 0.6 & 2.9 & 5.2 & 0.5 & 0.6 & 6.5 & 0.6 & 0.1 \\
\hline \multirow{2}{*}{\multicolumn{2}{|c|}{ Sub total }} & No & 577 & 113 & 134 & 103 & 408 & 384 & 51 & 57 & 132 & 75 & 13 \\
\hline & & $\%$ & 26.3 & 5.7 & 6.7 & 5.2 & 2.4 & 19.2 & 2.6 & 2.9 & 6.6 & 3.8 & 0.7 \\
\hline \multicolumn{3}{|c|}{ Total } & 1947 & & & & & & & & & & \\
\hline
\end{tabular}

*** House hold (HH), Hospital (HP), Bazar (BZR), Station (STN), Drain (DRN), Dairy shed (DS), Poultry farm (PF), Agricultural field (AGF), Saw mill (SM), Rice mill (RM), Mango garden (MN)

The scenario is quite different in adult mosquitoes (Table 4). Adult Culex mosquitoes were more concentrated in households $(22.2 \%)$ followed by drains $(18.0 \%)$ and dairy sheds $(13.3 \%)$, whereas adult Anopheles were more abundant in rice fields (6.5\%) followed by dairy sheds $(5.2 \%)$. Expanding agriculture might produce habitat characteristics favoured by Anopheles mosquitoes, specifically agricultural uses might increase the availability of the pools of water with little or no surrounding vegetation that are the preferred breeding sites for Anophles mosquitoes (Gimnig, 2001,Sinka, 2010).

The overall abundance of total mosquitoes was found highest in the households (26.4\%) followed by drains (20.4\%) and dairy sheds (19.22\%), whereas adult Anopheles was also abundant in rice fields. In this study Anopheles and Culex shared the same breeding places. There was a very strong positive association between the presence of anophelines and the presence of culicines. Similar findings have been reported from habitats in rural areas in East and West Africa (Fillinger et al. 2004) indicating that there is no clear separation between 'typical' Anopheles and Culex larval habitats. 
The prevalence of larval species of An. aconitus was the highest in drains $(2.4 \%)$ followed by dairy sheds (2.0\%). But Boewono et al. (1997) found An. aconitus more prevalent in households. An. aconitus generally resting in households, cattle shelters at night and resting in natural outdoors side at morning. In our study the difference may because of method and time of adult mosquito collection. In case of adult, An. vagus showed great prevalence in dairy sheds (2.6\%) due to presence of cow dung, urine and other polluted water bodies which is similar to the finding in Jahangirnagar University campus (Jannat, 2005).

Culex species were not observed in the fresh water bodies like fresh pond water, fresh river water etc. because the larvae of Culex species may prefer polluted ground water site like blocked drains, cesspools, shallow ponds, containers, jars, tree holes and other polluted water reservoirs which are very common in the study area. Rapid growth of human populations has been implicated in the increased presence of culicid vectors (Ravel et al., 2001). We did not found Aedes mosquitoes in Bagha Upazilla of Rajshahi during our study from July 2015 to May 2016. Possibly because of suitable fresh and clear water containing smaller habitats of Aedes mosquito was fewer in Bagha upazila during the study period.

From the survey it has been apparent that the polluted water bodies in the locality, e.g. semi-polluted ponds, drains, artificial reservoirs harbor most of the mosquitoes. Sometimes water bodies were found totally larvae free because of high chemical contamination that emerged from household activities, agriculture fertilizer and farm disinfection which destroyed the larvae readily.

\section{CONCLUSION}

The results of the study indicate that all the places studied here are very much vulnerable to mosquito-borne diseases. This study will help us detect the breeding sites of mosquitoes and to take necessary steps to control mosquitoes. Sometimes environmental variables could affect the occurrence and distribution of mosquitoes which were not determined during the study. Therefore, further research must be continued to know the ecology and control measures of the mosquito species.

\section{CONFLICT OF INTEREST}

There are no conflicts of interest in the present study.

\section{REFERENCES}

1. Akter F, Farjana T, Islam T, Khanom TF, Islam KR, Alim A, 2014. Seasonal distribution of mosquitoes (Diptera: Culicidae) in Bangladesh Agricultural University (BAU) campus, Mymensingh, Bangladesh. Bangladesh Veterinary Journal, 48 (1-4): 11-24.

2. Alam N, Farjana T, Khanom TF, Labony SS, Islam KR, Ahmmed S and Mondal MMH, 2015. Prevalence of mosquito species (Diptera: Culicidae) in and around Bangladesh Agricultural University campus, Mymensingh, Bangladesh. Progressive Agriculture, 16(1): 37-46.

3. Beaty BJ and Marquardt WC, 1996. The biology of Disease Vectors. $632 \mathrm{pp}$.

4. Boewono DT, Nalim S, Sularto T, Mujiono and Sukarno, 1997. Penentuan vector Malaria di Kecamatan Teluk Dalam, Nias. Cermin Dunia Kedokteran, No. 118

5. Bram RM, 1967. Contribution to the mosquito fauna to South-East Asia, II. The genus Culex in Thailand (Diptera; Culicidae).Contribution to American Entomological Institute, 2(1): 1-296.

6. CDC (Communicable Disease Control) Bangladesh, 2012. Annual report book. 125 pp.

7. Eldridge BF and Edman JD, 2000. Medical Entomology: A Textbook on Public Health and Veterinary Problems Caused by Arthropods. Kleuwer Academic Publishers, Dordrecht Chapter 2, pp. 13-51.

8. Farjana T, Ahmmed S, Khanom TF, Alam N and Begum N, 2015. Surveillance of mosquitoes larva at selected areas of Mymensingh District in Bangladesh. Bangladesh Journal of Veterinary Medicine, 13 (1): 79-88. 
9. Fillinger U, Sonye G, Killeen GF, Knols BG and Becker N, 2004. The practical importance of permanent and semipermanent habitats for controlling aquatic stages of Anopheles gambiae sensulato mosquitoes: operational observations from a rural town in western Kenya. Tropical Medicine and International Health, 9: 1274-1289.

10. Gimnig JE, Ombok M, Kamau L, Hawley WA, 2001. Characteristics of larval anopheline (Diptera: Culicidae) habitats in western Kenya. Journal of Medical Entomology, 38: 282-288.

11. ICDDR'B, 2009). First identified outbreak of Chikungunya in Bangladesh, 2008. Health Science Bulletin, 7: 1.

12. Jannat KNE, Baqui MA andAhmed TU, 2005. The status of dengue vector mosquitoAedes spp. in Dhaka. Bangladesh Journal of Life Science, 17(2): 15-23.

13. Manguin S, Bangs MJ, Pothikasikorn J, Chareonviriyaphap T, 2009. Review on global co-transmission of human Plasmodium species and Wuchereria bancrofti by Anopheles mosquitoes. Infection, Genetics and Evolution, 10: 159-177.

14. Meyer RP and Durso SL, 1998. Identification of the Mosquitoes of California. Mosquito and Vector Control Association of California, Elk Grove, CA.

15. Patz JA, Strzepek K, Lele S, Hedden M, others 1998: Predicting key malaria transmission factors, biting and entomological inoculation rates, using modeled soil moisture in Kenya. Tropical Medicine and International Health, 3: 818-827.

16. Ravel S, Monteny N, Olmos DV, Verdugo JE, Cuny G 2001: A preliminary study of the population genetics of Aedes aegypti (Diptera: Culicidae) from Mexico using microsatellite and AFLP markers. Acta Tropica, 78: 241-250.

17. Santiago ATA and Claveria FG, 2012. Medically important mosquitoes (Diptera: Culicidae) identified in rural Barangay Binubusan, Lian, Batangas Province, Philippines. Philippine Journal of Science, 141(1): 103-109.

18. Service MW, 1993. Mosquitoes (Culicidea), Lanes, R. P. and Cross key, R. W (Editors) Medical insects and Arachnids. Chapman and Hall, London. 238pp.

19. Sinka ME, Bangs MJ, Manguin S, 2010. The dominant Anopheles vectors of human malaria in Africa, Europe and the Middle East: occurrence data, distribution maps and bionomic précis. Parasite Vectors. 3: 117.

20. Tanaka K, Mizusawa K, Saugstad ES, 1979. A revision of the adult and larval mosquitoes of Japan (including the Ryukyu Archipelago and the Ogasawara Islands) and Korea (Diptera: Culicidae). Contribution of American Entomological Institute, 16: 1-987.

21. WHO (World Health Organization), 1996. Agricultural Development and Vector-borne 2007 from http://www.epa.sa.gov.au/pdfs/mosquitoes.pdf. 